\title{
Increased risk for hip fracture after death of a spouse-further support for bereavement frailty?
}

\author{
C. H. Vala ${ }^{1,2}$ - M. Lorentzon ${ }^{1,2,3} \cdot$ V. Sundh ${ }^{1} \cdot$ H. Johansson ${ }^{1,3} \cdot$ C. Lewerin ${ }^{4} \cdot$ S. Sten $^{5} \cdot$ M. Karlsson ${ }^{6} \cdot$ C. Ohlsson ${ }^{7}$. \\ B. Johansson ${ }^{8}$ • J. A. Kanis ${ }^{3,9} \cdot$ D. Mellström ${ }^{1,2,7}$
}

Received: 9 July 2019 / Accepted: 19 November 2019 / Published online: 12 December 2019

(C) The Author(s) 2019

\begin{abstract}
Summary Death of a spouse is associated with poorer physical and mental health. We followed all married individuals, born from 1902 to 1942, during the period from 1987 to 2002, and found that widows and widowers had higher risk for hip fracture, compared with still married women and men.

Introduction Spousal bereavement can lead to poorer physical and mental health. We aimed to determine whether married women and men had an elevated risk of hip fracture after death of a spouse.

Methods In a retrospective cohort study, we followed all Swedish married individuals aged 60 to 100 years $(n=1,783,035)$, from 1987 to 2002. Data are presented as mean with $95 \%$ confidence interval (CI).

Results During the follow-up period, 21,305 hip fractures among widows and 6538 hip fractures among widowers were noted. The hazard ratio (HR) for hip fracture in widows compared with married women was 1.34 (95\% CI 1.31 to 1.37 ) and for widowers compared with married men 1.32 (95\% CI 1.29 to 1.35). The HR for hip fracture in the first 6 months after death of a spouse was in widows compared with married women 1.62 (95\% CI 1.53 to 1.71) and in widowers compared with married men 1.84 (95\% CI 1.68 to 2.03). The elevated risk was especially prominent in young widowers in the age range 60-69 years. During the first 6 months they showed a HR of 2.76 (95\% CI 1.66 to 4.58) for a hip fractvure compared with age matched married men. Widows aged 60-69 years showed a HR of 1.59 (95\% CI 1.26 to 1.99) compared with age matched married women.

Conclusion Our observation of a higher hip fracture risk in both genders in connection with the death of a spouse indicates a possible effect of bereavement on frailty.
\end{abstract}

Keywords Bereavement $\cdot$ Hip fracture $\cdot$ Osteoporosis $\cdot$ Widow $\cdot$ Widower $\cdot$ Widowhood

Electronic supplementary material The online version of this article (https://doi.org/10.1007/s00198-019-05242-w) contains supplementary material, which is available to authorized users.

\section{H. Vala}

cecilie.hongslo.vala@gu.se

1 Geriatric Medicine, Department of Internal Medicine and Clinical Nutrition, Sahlgrenska Academy, University of Gothenburg, 413 45 Göteborg, Sweden

2 Region Västra Götaland, Geriatric Medicine Clinic, Sahlgrenska University Hospital, 43180 Mölndal, Sweden

3 Mary McKillop Health Institute, Australian Catholic University, Melbourne, Australia

4 Section of Haematology and Coagulation, Department of Internal Medicine and Clinical Nutrition, Sahlgrenska University Hospital, 41345 Gothenburg, Sweden
5 Department of Archaeology and Ancient History, Uppsala University-Campus Gotland, 62157 Visby, Sweden

6 Department of Orthopedics and Clinical Sciences, Skåne University Hospital, Lund University, 20502 Malmö, Sweden

7 Center for Bone and Arthritis Research (CBAR), Sahlgrenska Academy, University of Gothenburg, 41345 Gothenburg, Sweden

8 Department of Psychology, University of Gothenburg, 405 30 Gothenburg, Sweden

9 Centre for Metabolic Bone Disease, Medical School, University of Sheffield, Sheffield S10 2RX, UK 


\section{Introduction}

Bereavement, in the form of becoming a widow or widower, is a major life event associated with an increased risk for compromised physical and mental health, as well as mortality [1]. Health problems as results of bereavement may include depression, anxiety, illness, sleep disturbance, and increased intake of medications [1-5].

Several studies have shown an increased use of psychotropic medication after bereavement $[1,2]$. A Swedish study of 658,022 individuals showed an increased risk of death, use of psychiatric care, and psychotropic medication after loss of spouse compared with married individuals. Individuals who newly lost their spouse had a $46 \%$ odds ratio (OR) (95\% confidence interval (CI) 1.41 to 1.50 ) and increased risk for prescribed psychotropic medication [1]. The combined interactions of compromised overall health, both mentally and physically, and medications are likely to produce an increased risk for adverse effects, including falls and fractures. Several studies have presented evidence for a connection between selective serotonin reuptake inhibitors (SSRIs) and fractures and falls, with two large meta-analysis showing an approximately $70 \%$ increased risk of fracture among SSRIs users [6-10]. A Norwegian study of 250 patients with hip fracture, aged $\geq 65$ years, showed a more frequent use of antidepressants and benzodiazepines among the hip fracture patients compared with the general elderly population in the same ages [11].

Stressful life events have been shown to increase the risk of loss of bone mass in the hip [12] and falls [13]. Notable, the risk increased with the number and types of stressful life events. A stressful event might for example be a hip fracture in spouse. In a previous study, using the same population as used in the present study, we found a higher risk of hip fracture among women and men whose spouse had a hip fracture, possibly due to assortative mating and shared lifestyle and environment [14]. Hip fracture is a major public health concern, especially in Sweden with one of the worldwide highest known annually incidence rates of hip fracture [15]. Besides the direct functional consequences associated with a hip fracture, there are also studies showing an increased risk for mortality and high healthcare costs [15].

Bereavement is even associated with an increased risk of mortality, although the excess mortality seems to decrease over time $[16,17]$.

The present study was designed to determine the risk of hip fracture after the death of a spouse, given the well-documented risks of hip fractures in Sweden and previous findings that bereavement is a risk factor for compromised mental and physical health.

\section{Population and methods}

\section{Cohort}

We followed all married women and men aged 60 to 100 years during the time period from 1987 to $2002(n=1,783,035)$, using data retrieved from different national registers at Statistic Sweden; the Swedish Total Population Register, the Swedish Census Register from 1970 to 1990, the Swedish National Inpatient Register (originally from the Swedish National Board of Health and Welfare). The Swedish Tax Agency gathers all information on change of marital status, death, migration, and immigration, and sent this information directly to the Statistic Sweden.

The individuals were registered as married throughout the years from 1982 to 1986 . The mean age difference for all spouses was 3.9 years, with a correlation coefficient in age of 0.90 . For $95 \%$ of the married couples, the age difference between partners was less than 11 years, for $75 \%$ less than 6 years, and for $55 \%$ it was less than 4 years.

The population segments at our focus were women and men whose spouse had died during the follow-up period; their risk time started on the day of the death of their spouse. The control population consisted of still married women and men. The couples that divorced during the follow-up period remained in the control group. Furthermore, we only included events from the age of 60 years and later in life, since hip fractures and death of spouse are quite rare events at younger ages. After excluding persons with risk time terminating prior to age 60 , because of hip fracture or death, our population comprised 891,181 women and 891,854 men. In the followup period, 299,067 (17\%) women and 128,344 (7.2\%) men became widows and widowers, respectively.

\section{Outcomes}

We studied all admissions to hospitals in Sweden due to hip fracture between the period January 1987 and December 2002. For all individuals in the study, only the first hip fracture during follow-up period was registered. To avoid multiple admissions for hip fracture, a unique personal identifier was used to track individuals. All patients in the register were required to have a diagnosis code for the following hip fracture types: femoral neck fracture, intertrochanteric fracture, and sub-trochanteric fracture (ICD-9820A-D or ICD-10 S720-S722) and a surgical procedure code related to hip fracture (ICD-98200-8219, 8413-8414 or ICD-10 NFB and NFJ). The Swedish National Inpatient Register, operated by the National Board of Health and Welfare, continually registers all hospital admission in Sweden. The register includes information on admission and discharge date, hospital and clinic, diagnosis, and surgical procedure codes from the International 
Classification of Diseases (ICD). For surgical admissions, the registration has an accuracy that exceeds 90\% [18].

\section{Covariates}

Data was adjusted for age, calendar year of fracture, income, level of urbanisation and place of residence, geographical latitude, and previous hip fracture in spouse. The exact age was calculated for all individuals in each risk period, which consisted of approximately 60 days. We had income data from the years 1991, 1996, and 2002 for all individuals except for $7.1 \%$ of the men and $3 \%$ of the women. The highest registered income level, adjusted for inflation, was used and calculated on quintiles for each 10-year birth group. We categorised the education level on a 7-point scale; level 1 is $<9$ years in school and level 7 is postgraduate education. For the individuals born before 1930, low education was defined as being in level 1 and for those born 1930 or later being in level 1 or 2. Among older individuals, shorter education was more common. There were no data on education level available for those born from 1902 to 1910 , which was the fact for $1 \%$ in the later born cohorts. Information on level of urbanisation and geographical latitude were available for all individuals. We calculated the urbanization degree from a 6-point scale; 1 is $>200,000$ inhabitants per municipality and 6 are $<15,000$ inhabitants. There were missing data on income or education for $15 \%$ of the men and $8 \%$ of the women. Corresponding numbers for cohorts born from 1912 to 1942 were $6.0 \%$ of the men and $3.0 \%$ of the women.

In the initial analyses, we included education as a covariate, but in the subsequent steps it was excluded as it turned out to be a non-significant covariate with minor effects on the outcome (women hazard ratio (HR) 1.00; 95\% CI 0.98 to 1.02 , men HR $0.97 ; 95 \%$ CI 0.95 to 1.00). Inclusion of education as a covariate also produced a population with lower rates of hip fractures, especially among older individuals. We had no information on other diseases than musculoskeletal diseases. We had information on day of death, but not on cause of death.

\section{Statistical analysis}

Married women and men were followed in the Swedish National Inpatient Register from January 1, 1987 to December 31, 2002, a total of 23,950,449 risk years, to capture the first event of hip fracture. We presumed that the admission date to the hospital was the same as the fracture date. The total risk time in the bereaved group was $1,856,698$ years for widows and 652,440 years for widowers. The total risk time in the control group was 10,693,309 years for married women and 10,748,002 years for married men.

To analyse the relationship on the risk of hip fracture, all the covariates and death of a spouse were used as time dependent covariates, stratified by age and sex, according to the extension of the Poisson regression model [19]. Compared with a logistic regression model, the Poisson regression model provides the advantage of taking the length of the follow-up period for each individual into account. The risk period for each individual ( 0 to 16 years) was further subcategorised into 2-month periods, or more precisely into periods with the length of $1 / 6$ th of a year or 60.83 days. Our results are presented as HR with $95 \%$ CI. The results can be compared with outcomes from a Cox proportional hazard model.

\section{Results}

During the follow-up period, from 1987 to 2002, hip fracture occurred in 86,168 married and widowed individuals aged 60 to 100 years; 53,647 women and 32,521 men (Table 1). Among the widows, $13.1 \%$ sustained a hip fracture on the first year after bereavement. The corresponding number in widowers was $16.0 \%$. The incidence for hip fracture the first year after death of a spouse was 10.45 per 1000 years in both widows and widowers separately. In general, the mean age of becoming a widow is lower than in becoming a widower, which explains the same incidence for hip fracture.

The mean age for widows was 75.6 ( \pm 7.7 standard deviation (SD) years and widowers $78.0( \pm 8.0 \mathrm{SD})$ years, for married women 67.7 ( $\pm 6.4 \mathrm{SD})$ years, and for married men 70.0 $( \pm 7.1 \mathrm{SD})$ years (Table 1$)$. The mean age for hip fracture among widows was $82.3( \pm 6.2 \mathrm{SD})$ years, for still married women $76.6( \pm 7.1 \mathrm{SD})$ years, in widowers $84.0( \pm 6.3 \mathrm{SD})$ years, and in still married men $79.0( \pm 7.2 \mathrm{SD})$ years.

During the 16 years of follow-up, only $2.5 \%$ of all the married couples divorced. Of the women in the control group $3.4 \%$ were divorced during follow-up, the corresponding number for men was $2.9 \%$. We performed a sensitivity analysis, which showed that the loss of risk time after divorce only excluded $0.8 \%$ of the number of hip fractures in women and $1.1 \%$ in men. The proportion of risk time as divorced only accounted for $1.7 \%$ and $1.6 \%$ for women and men, respectively. Thus, excluding divorce did not affect our results.

The HR for hip fracture for the whole follow-up period was for women 1.34 (95\% CI 1.31 to 1.37) and for men 1.32 (95\% CI 1.29 to 1.35 ), after death of spouse, compared with married whose spouse remained alive.

Studying the risk of hip fracture over time in both women and men, we observed the highest risk the first 6 months after bereavement, $62 \%$ in widows and $84 \%$ in widowers, with a decreasing trend after 6 months, compared with non-bereaved individuals (Tables 2 and 3 ). After 3 years, the risk remained stable at a significantly elevated level in women and after 4 years in men, compared with non-bereaved individuals (Tables 2 and 3). The risk of hip fracture in women was $8 \%$ higher the first half year after bereavement (95\% CI 1.011.16) compared with the second half year. Corresponding 
Table 1 Baseline characteristics for widows/widowers and still married women/men

\begin{tabular}{|c|c|c|c|c|}
\hline & $\begin{array}{l}\text { Widow } \\
n=299,067\end{array}$ & $\begin{array}{l}\text { Widower } \\
n=128,344\end{array}$ & $\begin{array}{l}\text { Married women } \\
n=592,114\end{array}$ & $\begin{array}{l}\text { Married men } \\
n=763,510\end{array}$ \\
\hline Mean age (years) & $75.6 \pm 7.7$ & $78.0 \pm 8.0$ & $67.7 \pm 6.4$ & $70.0 \pm 7.1$ \\
\hline Hip fracture & $21,305(7.1 \%)$ & $6538(5.1 \%)$ & $32,342(5.5 \%)$ & $25,983(3.4 \%)$ \\
\hline \multicolumn{5}{|l|}{ Income } \\
\hline Lowest quintile & $20 \%$ & $5 \%$ & $41 \%$ & $6 \%$ \\
\hline 2nd quintile & $29 \%$ & $6 \%$ & $27 \%$ & $8 \%$ \\
\hline 3rd quintile & $22 \%$ & $18 \%$ & $16 \%$ & $20 \%$ \\
\hline 4th quintile & $16 \%$ & $32 \%$ & $10 \%$ & $29 \%$ \\
\hline Highest quintile & $13 \%$ & $38 \%$ & $6 \%$ & $37 \%$ \\
\hline \multicolumn{5}{|l|}{ Education } \\
\hline$\leq 9$ years & $69 \%$ & $62 \%$ & $55 \%$ & $53 \%$ \\
\hline $10-12$ years & $27 \%$ & $32 \%$ & $37 \%$ & $38 \%$ \\
\hline University & $4 \%$ & $6 \%$ & $8 \%$ & $9 \%$ \\
\hline \multicolumn{5}{|l|}{ Latitude } \\
\hline South & $22 \%$ & $21 \%$ & $22 \%$ & $22 \%$ \\
\hline Middle-south & $49 \%$ & $49 \%$ & $50 \%$ & $50 \%$ \\
\hline Middle-north & $18 \%$ & $19 \%$ & $17 \%$ & $17 \%$ \\
\hline North & $11 \%$ & $11 \%$ & $11 \%$ & $11 \%$ \\
\hline \multicolumn{5}{|c|}{ Population density (000) } \\
\hline$>200 / \mathrm{S}$ & $15 \%$ & $16 \%$ & $14 \%$ & $14 \%$ \\
\hline $50-200 / \mathrm{M}$ & $31 \%$ & $30 \%$ & $32 \%$ & $32 \%$ \\
\hline $15-50 / \mathrm{L}$ & $36 \%$ & $36 \%$ & $37 \%$ & $37 \%$ \\
\hline$<15$ & $18 \%$ & $18 \%$ & $17 \%$ & $17 \%$ \\
\hline
\end{tabular}

numbers for men were $14.0 \%$ higher risk for hip fracture $(95 \%$ CI 1.01-1.29).

Finally, we subdivided our studied population into age cohorts. The highest HR for hip fracture after death of a spouse was found in the age group 70-79 years for women (increased by $75 \%$ ) and in the age group 60-69 years among men (HR 2.76). The HR declined with increasing age, and the lowest HR was found in the oldest age range (Table 4).

Table 2 Hazard ratios (with 95\% CI) for risk of hip fracture in women after death of a spouse, compared with still married women according to different time intervals

\begin{tabular}{lll}
\hline Time & HR $(95 \% \mathrm{CI})^{\mathrm{a}}$ & HR $(95 \% \mathrm{CI})^{\mathrm{b}}$ \\
\hline Month 0-6 & $1.49(1.41$ to 1.57$)$ & $1.62(1.53$ to 1.71$)$ \\
Month 6-12 & $1.37(1.30$ to 1.45$)$ & $1.51(1.43$ to 1.60$)$ \\
Year 2 & $1.34(1.28$ to 1.40$)$ & $1.47(1.41$ to 1.54$)$ \\
Year 3 & $1.24(1.19$ to 1.30$)$ & $1.38(1.32$ to 1.45$)$ \\
Year 4 & $1.22(1.17$ to 1.28$)$ & $1.36(1.30$ to 1.42$)$ \\
Over 5 years & $1.26(1.23$ to 1.30$)$ & $1.38(1.34$ to 1.42$)$ \\
\hline
\end{tabular}

a adjusted for age and calendar year

${ }^{b}$ adjusted for age, calendar year, income, latitude, urbanisation, and previous hip fracture in spouse

\section{Discussion}

We demonstrate in this study a finding of an increased risk of hip fracture after death of a spouse. The risk was $62 \%$ higher in widows and $84 \%$ higher in widowers during the first 6 months after bereavement. Noteworthy, the risk for hip fracture were more prominent at younger ages and in widowers. The hip fracture risk among widows and widowers gradually decreased after the first 6 months, but remained significantly

Table 3 Hazard ratios (with 95\% CI) for risk of hip fracture in men after death of a spouse compared with still married men according to different time intervals

\begin{tabular}{lll}
\hline Time & HR $(95 \% \mathrm{CI})^{\mathrm{a}}$ & HR $(95 \% \mathrm{CI})^{\mathrm{b}}$ \\
\hline Month 0-6 & $1.86(1.69$ to 2.04$)$ & $1.84(1.68$ to 2.03$)$ \\
Month $6-12$ & $1.63(1.50$ to 1.77$)$ & $1.60(1.47$ to 1.74$)$ \\
Year 2 & $1.57(1.47$ to 1.67$)$ & $1.54(1.44$ to 1.64$)$ \\
Year 3 & $1.51(1.41$ to 1.62$)$ & $1.50(1.40$ to 1.61$)$ \\
Year 4 & $1.38(1.27$ to 1.51$)$ & $1.38(1.27$ to 1.50$)$ \\
Over 5 years & $1.37(1.31$ to 1.43$)$ & $1.33(1.28$ to 1.38$)$
\end{tabular}

${ }^{a}$ adjusted for age and calendar year

$\mathrm{b}$ adjusted for age, calendar year, income, latitude, urbanisation, and previous hip fracture in spouse 
Table 4 Hazard ratios (with 95\% CI) for risk of hip fracture in women and men after death of a spouse compared with married women and men, the first 6 months after bereavement, stratified by age

\begin{tabular}{lll}
\hline Age & Women HR $(95 \% \mathrm{CI})$ & Men HR $(95 \% \mathrm{CI})$ \\
\hline $60-69$ & $1.59(1.26$ to 1.99$)$ & $2.76(1.66$ to 4.58$)$ \\
$70-79$ & $1.75(1.61$ to 1.91$)$ & $1.89(1.54$ to 2.33$)$ \\
$80-89$ & $1.45(1.34$ to 1.57$)$ & $1.87(1.66$ to 2.11$)$ \\
$90-100$ & $1.16(0.91$ to 1.49$)$ & $1.34(1.02$ to 1.76$)$ \\
\hline
\end{tabular}

The models were adjusted for age, calendar year, latitude, urbanisation, income, and previous hip fracture in spouse

higher than the control population. After 3 years we found a $36 \%$ higher risk ratio for widows and after 4 years a $38 \%$ higher risk ratio among widowers. Our findings are in line with a previous Swedish study that included 1327 incident hip fracture and 3262 control women aged 50-81 years, and followed during the time period 1993-1995. The study showed an increased risk for hip fracture in widows (OR $1.45 ; 95 \%$ CI 1.07 to 1.95 ) [20]. Taken together, these two studies indicate that bereavement, as a major stressful life event, substantially can increase the risk for certain fractures.

\section{Stressful life events and bone}

Stressful life events have been associated with accelerated bone loss, incident falls, and fractures, but only $1.5 \%$ had experienced a recent bereavement $[12,13]$. A large study of women showed that women with mental distress had a relative risk (RR) of 1.95 for hip fracture. Feelings of loneliness were associated with an $85 \%$ increase in hip fracture risk [21]. An earlier study showed that loneliness among older adults is strongly associated with widowhood [22].

\section{Bereavement and mortality}

A study of all Swedish individuals from age 50 to 90 years followed from 1968 to 1978 (360,000 widows and widowers) showed that widows had a $22 \%$ increased mortality and widowers $48 \%$ increased mortality in the first 3 months after death of a spouse. Cardiovascular disease and cancer were accounted for the largest proportion of the excess mortality among widows and widowers. Compared with married men, widowers also had an excess mortality from lung cancer, liver cirrhosis, and accidental falls [23]. An increased mortality following bereavement is confirmed in several studies [24-27]. In our analysis, mortality does not affect the risk of hip fracture at an individual level, only on the total number of observed cases at the end of the risk period. This parameter is not analysed in this study.

\section{Bereavement and physiological effects}

Bereavement is one of the most stressful life events a person can experience. The extended stress that often accumulates over a long period before, as well as after death of a spouse, has been associated with a negative neuroendocrine response. One of the first studies of abnormalities in the immune system after bereavement showed a reduced T-lymphocyte response to mitogenic stimulation [28]. Bereavement has also been associated with increased systemic inflammation through elevated levels of the genetic inflammatory markers IL-1RA and IL-6, due to a genetic reaction to stress [29]. Two Australian studies have shown that bereavement in the early stages was associated with inflammatory and prothrombotic alteration, which can increase the risk of cardiovascular diseases, increased heart rate and systolic blood pressure, elevated levels of cortisol in the morning, elevated depression, and anger [30,31]. Increased cortisol levels in the mornings occur at least in the first 6 months after bereavement, often accompanied with decreased levels of dehydroepiandrosterone (DHEA) [3]. Studies have shown an increased risk for falls and fractures in older men with low levels of DHEA [32, 33]. When compared with married ones, widows were more likely to demonstrate worse coping behaviour in terms of more smoking and drinking. Widows were also more likely to have high blood pressure and diabetes, heart disease, stroke, and a lower physical activity level [34]. An Australian study showed that $86 \%$ of women who recently lost their husband were suffering from one or more chronic conditions, and in early bereavement the majority experienced a worsening of their condition or were diagnosed with a new condition [35]. The excess mortality as well as compromised mental and physical health among newly bereaved in widows and widowers is documented in several studies. However, few clinical diagnoses have been associated with the first 6 months of bereavement. One exception is stress cardiomyopathy or Takotsubo cardiomyopathy where bereavement and other severe stressful events are overrepresented [36], and it has been shown that low levels of DHEA predict incident coronary heart disease in men [37].

\section{Bereavement and mental health}

Sleep disturbance can occur in 32-36\% of the individuals over the age of 60 years, but are more prevalent in individuals with mental and physical problems, and among those exposed to psychosocial stress such as bereavement [38]. Several studies have reported sleep disturbance in bereaved spouses, especially in depressed individuals and in the immediate period following the death of a spouse [35, 39]. Short sleep duration and poor sleep quality have been shown to be associated with recurrent falls (increased $27 \%$ and $11-21 \%$, respectively) and all types of fractures (increased $10 \%$ and $0-4 \%$, 
respectively), but not with hip fracture alone [40]. Hallucinations can also be a symptom of severe and longstanding stress after bereavement, and is experienced in as many as approximately $40-80 \%$ of the bereaved [38]. Another study found that $28 \%$ of the spousal bereaved also experienced a major depression; the risk was highest during the first 6 months after bereavement [39]. An American study reported that $83 \%$ of bereaved spouses with major depression did not receive any antidepressants [41]. This is an older study and the numbers might now differ, but depression among bereaved is probably still underdiagnosed and therefore untreated in many cases. In a study of long-term effects of widowhood, widows also had an increased risk of economic dissatisfaction, diabetes (RR 3.5; 95\% CI 1.2 to 7.9), anxiety (RR $1.9 ; 95 \%$ CI 1.3 to 2.7 ), depression (RR 2.2; 95\% CI 1.6 to 2.9), and sleep disturbance (RR 1.9; 95\% CI 1.5 to 2.4) [42].

\section{Bereavement and medication}

A Norwegian study of 18,612 women, aged 50 years and older, showed that mental distress and daily use of medication (tranquillisers/sedatives or hypnotics) increased the risk of hip fracture. When only adjusting for age, the RR for hip fracture with daily use of tranquillisers/sedatives or hypnotics was 2.11 (95\% CI 1.55 to 2.86). Notably, when adjusting for all covariates (age, BMI, mental distress, use of medication, smoking, physical inactivity, and impairment due to physical illness) the RR was not significantly different from the control population $(1.48 ; 95 \%$ CI 0.99 to 2.21) [21]. Prolonged stress with poor sleep, depression, and anxiety may lead to treatment with selective serotonin reuptake inhibitors (SSRI), which in turn can increase risk of falls and fracture $[6,43]$. There is a strong relationship between SSRIs and fracture, but most studies are observational in nature, which mean that causal relationships between medications and fractures are yet to be established [8].

\section{Possible explanations and implications}

We anticipate that the severe and longstanding stress during the first 6 months after bereavement, but perhaps also a period before death, is the main cause of increased risk for hip fracture. Increased levels of cortisol and low levels of DHEA, increased inflammation, and increased heart rate and blood pressure are possible physiological mechanisms. Mental distress including depression, anxiety, sleeping disorders, and hallucinations might contribute to the increase in consumption of tranquillisers, antidepressants, and alcohol. Other factors contributing to the increased hip fracture risk might be shared lifestyle and environment, and assortative mating, in terms of diet, weight, unhealthy behaviours such as smoking, drinking, and low physical activity. The stress produced by bereavement might also reflect the overall life circumstances experienced long before the death of the spouse. For example, the spouse might have been in bad health long before death, with a history of previous surgery and hospital admission. The wife or husband might have had the role of a caregiver, with obligations to care for many other needs of the spouse. Studies have shown that individuals caring for a sick and dying spouse or family member, often experience depression, anxiety, fatigue, and physical and emotional strain [44-46]. Physical and mental comorbidity, chronic stress, and unhealthy behaviours are most likely contributors to the elevated level of hip fracture risk seen several years after bereavement.

\section{Strengths and limitations of the study}

The main strengths of this population-based study include a large sample consisting of all married women and men born from 1902 to 1942 , the long follow-up time from 1987 to 2002 , and the high validity of the information retrieved from the Swedish registers. Data from the entire country became available from 1987. The risk time starts on the day the individuals became widows or widowers during the follow-up period, so risk time before death of spouse is not included in the analysis.

An obvious limitation is that we are unable to present the mechanisms and the pathophysiological pathways underlying our observed relations between the elevated risk for hip fracture and bereavement. Data on comorbidities were not available for the analyses. There were also some limitations in missing data on the level of educational attainment, but this mostly affected the oldest individuals, and adjustment for education did not alter our results. We had no information on common-law relationships, who would most likely experience similar bereavement effects as spouses.

\section{Conclusion}

We demonstrate a finding of a higher risk for hip fracture during the first 6 months after bereavement. The hip fracture risk was higher in both widows and widowers compared with still married women and men. Especially high was the risk for hip fracture in younger men. After the first 6 months there was a gradually decrease in HR, but even so, an excess risk persisted at a significantly higher level for several years. In the present study, we demonstrate that early bereavement is associated with a higher risk to sustain a broken hip.

Acknowledgements We are grateful to Professor Anders Odén and the late Professor Olof Johnell for their contribution to the data collection.

Funding information Open access funding provided by University of Gothenburg. This study was funded by the Swedish government under the agreement between the Swedish government and the county councils (ALFGBG722321 and ALFGBG437971), and the Swedish Research Council (2017-02229). 


\section{Compliance with ethical standards}

\section{Conflicts of interest None.}

Ethical approval All procedures performed in studies involving human participants were in accordance with the ethical standards of the institutional and/or National Research Committee and with the 1964 Helsinki declaration and its later amendments or comparable ethical standards. For this study, we received de-identified data registers from the Statistics Sweden. Ethical approval was granted by the regional ethics committee in Lund, Sweden (LU 630-99). Since this is a retrospective study, formal consent was not needed.

Open Access This article is distributed under the terms of the Creative Commons Attribution-NonCommercial 4.0 International License (http:// creativecommons.org/licenses/by-nc/4.0/), which permits any noncommercial use, distribution, and reproduction in any medium, provided you give appropriate credit to the original author(s) and the source, provide a link to the Creative Commons license, and indicate if changes were made.

\section{References}

1. Moller J, Bjorkenstam E, Ljung R, Yngwe MA (2011) Widowhood and the risk of psychiatric care, psychotropic medication and allcause mortality: a cohort study of 658,022 elderly people in Sweden. Aging Ment Health 15(2):259-266. https://doi.org/10. 1080/13607863.2010.513041

2. Oksuzyan A, Jacobsen R, Glaser K, Tomassini C, Vaupel JW, Christensen K (2011) Sex differences in medication and primary healthcare use before and after spousal bereavement at older ages in Denmark: nationwide register study of over 6000 bereavements. J Aging Res 2011:678289. https://doi.org/10.4061/2011/678289

3. Buckley T, Sunari D, Marshall A, Bartrop R, McKinley S, Tofler G (2012) Physiological correlates of bereavement and the impact of bereavement interventions. Dialogues Clin Neurosci 14(2):129139

4. Buckley T, McKinley S, Tofler G, Bartrop R (2010) Cardiovascular risk in early bereavement: a literature review and proposed mechanisms. Int J Nurs Stud 47(2):229-238. https://doi.org/10.1016/j. ijnurstu.2009.06.010

5. Jho HJ, Choi JY, Kwak KS, Chang YJ, Ahn EM, Park EJ, Paek SJ, Kim KM, Kim SH (2016) Prevalence and associated factors of anxiety and depressive symptoms among bereaved family members of cancer patients in Korea: a nation-wide cross-sectional study. Medicine 95(22):e3716. https://doi.org/10.1097/MD. 0000000000003716

6. Eom CS, Lee HK, Ye S, Park SM et al (2012) Use of selective serotonin reuptake inhibitors and risk of fracture: a systematic review and meta-analysis. J Bone Miner Res 27(5):1186-1195. https://doi.org/10.1002/jbmr.1554

7. Kristjansdottir HL, Lewerin C, Lerner UH, Waern E et al (2018) High serum serotonin predicts increased risk for hip fracture and nonvertebral osteoporotic fractures: the MrOS Sweden study. J Bone Miner Res. https://doi.org/10.1002/jbmr.3443

8. Warden SJ, Fuchs RK (2016) Do selective serotonin reuptake inhibitors (SSRIs) cause fractures? Curr Osteoporos Rep 14(5):211218. https://doi.org/10.1007/s11914-016-0322-3

9. Du Y, Wolf IK, Knopf H (2017) Association of psychotropic drug use with falls among older adults in Germany. Results of the German health interview and examination survey for adults 2008-
2011 (DEGS1). PLoS One 12(8):e0182432. https://doi.org/10. 1371/journal.pone. 0182432

10. Wu Q, Bencaz AF, Hentz JG, Crowell MD (2012) Selective serotonin reuptake inhibitor treatment and risk of fractures: a metaanalysis of cohort and case-control studies. Osteoporos Int 23(1): 365-375. https://doi.org/10.1007/s00198-011-1778-8

11. Waade RB, Molden E, Martinsen MI, Hermann M, Ranhoff AH (2017) Psychotropics and weak opioid analgesics in plasma samples of older hip fracture patients-detection frequencies and consistency with drug records. Br J Clin Pharmacol 83(7):1397-1404. https://doi.org/10.1111/bcp.13244

12. Fink HA, Kuskowski MA, Cauley JA, Taylor BC, Schousboe JT, Cawthon PM, Ensrud KE, Osteoporotic Fractures in Men (MrOS) Study Group (2014) Association of stressful life events with accelerated bone loss in older men: the osteoporotic fractures in men (MrOS) study. Osteoporos Int 25(12):2833-2839. https://doi.org/ 10.1007/s00198-014-2853-8

13. Fink HA, Kuskowski MA, Marshall LM (2014) Association of stressful life events with incident falls and fractures in older men: the osteoporotic fractures in men (MrOS) study. Age Ageing 43(1): 103-108. https://doi.org/10.1093/ageing/aft117

14. Vala CH, Oden A, Lorentzon M, Sundh V et al (2017) Increased risk of hip fracture among spouses-evidence of a homogamy effect. Osteoporos Int 28(1):95-102. https://doi.org/10.1007/s00198-0163738-9

15. Hernlund E, Svedbom A, Ivergard M, Compston J et al (2013) Osteoporosis in the European Union: medical management, epidemiology and economic burden. A report prepared in collaboration with the International Osteoporosis Foundation (IOF) and the European Federation of Pharmaceutical Industry Associations (EFPIA). Arch Osteoporos 8(1-2):136. https://doi.org/10.1007/ s11657-013-0136-1

16. Moon JR, Kondo N, Glymour MM, Subramanian SV (2011) Widowhood and mortality: a meta-analysis. PLoS One 6(8): e23465. https://doi.org/10.1371/journal.pone.0023465

17. Brenn T, Ytterstad E (2016) Increased risk of death immediately after losing a spouse: cause-specific mortality following widowhood in Norway. Prev Med 89:251-256. https://doi.org/10.1016/j. ypmed.2016.06.019

18. Ludvigsson JF, Andersson E, Ekbom A, Feychting M, Kim JL, Reuterwall C, Heurgren M, Olausson PO (2011) External review and validation of the Swedish national inpatient register. BMC Public Health 11:450. https://doi.org/10.1186/1471-2458-11-450

19. Breslow NE, Day NE (1987) Statistical methods in cancer research: volume II-the design and analysis of cohort studies. IARC Sci Publ 82:1-406

20. Farahmand BY, Persson PG, Michaelsson K, Baron JA et al (2000) Socioeconomic status, marital status and hip fracture risk: a population-based case-control study. Osteoporos Int 11(9):803-808

21. Forsen L, Meyer HE, Sogaard AJ, Naess S et al (1999) Mental distress and risk of hip fracture. Do broken hearts lead to broken bones? J Epidemiol Community Health 53(6):343-347. https://doi. org/10.1136/jech.53.6.343

22. Berg S, Mellstrom D, Persson G, Svanborg A (1981) Loneliness in the Swedish aged. J Gerontol 36(3):342-349

23. Mellstrom D, Nilsson A, Oden A, Rundgren A et al (1982) Mortality among the widowed in Sweden. Scand J Soc Med 10(2):33-41

24. Lichtenstein P, Gatz M, Berg S (1998) A twin study of mortality after spousal bereavement. Psychol Med 28(3):635-643

25. Shor E, Roelfs DJ, Curreli M, Clemow L, Burg MM, Schwartz JE (2012) Widowhood and mortality: a meta-analysis and meta-regression. Demography 49(2):575-606. https://doi.org/10.1007/s13524012-0096-x

26. Lund R, Holstein BE, Osler M (2004) Marital history from age 15 to 40 years and subsequent 10 -year mortality: a longitudinal study 
of Danish males born in 1953. Int J Epidemiol 33(2):389-397. https://doi.org/10.1093/ije/dyh065

27. Martikainen P, Valkonen T (1996) Mortality after death of spouse in relation to duration of bereavement in Finland. J Epidemiol Community Health 50(3):264-268. https://doi.org/10.1136/jech. 50.3.264

28. Bartrop RW, Luckhurst E, Lazarus L, Kiloh LG, Penny R (1977) Depressed lymphocyte function after bereavement. Lancet 1(8016): 834-836

29. Schultze-Florey CR, Martinez-Maza O, Magpantay L, Breen EC et al (2012) When grief makes you sick: bereavement induced systemic inflammation is a question of genotype. Brain Behav Immun 26(7):1066-1071. https://doi.org/10.1016/j.bbi.2012.06.009

30. Buckley T, Mihailidou AS, Bartrop R, McKinley S et al (2011) Haemodynamic changes during early bereavement: potential contribution to increased cardiovascular risk. Heart Lung Circ 20(2): 91-98. https://doi.org/10.1016/j.hlc.2010.10.073

31. Buckley T, Morel-Kopp MC, Ward C, Bartrop R, McKinley S, Mihailidou AS, Spinaze M, Chen W, Tofler G (2012) Inflammatory and thrombotic changes in early bereavement: a prospective evaluation. Eur J Prev Cardiol 19(5):1145-1152. https:// doi.org/10.1177/1741826711421686

32. Ohlsson C, Nethander M, Kindmark A, Ljunggren O et al (2017) Low serum DHEAS predicts increased fracture risk in older men: the MrOS Sweden study. J Bone Miner Res 32(8):1607-1614. https://doi.org/10.1002/jbmr.3123

33. Ohlsson C, Nethander M, Karlsson MK, Rosengren BE et al (2018) Serum DHEA and its sulfate are associated with incident fall risk in older men: the MrOS Sweden study. J Bone Miner Res 33(7):12271232. https://doi.org/10.1002/jbmr.3418

34. Lee S, Cho E, Grodstein F, Kawachi I, Hu FB, Colditz GA (2005) Effects of marital transitions on changes in dietary and other health behaviours in US women. Int J Epidemiol 34(1):69-78. https://doi. org/10.1093/ije/dyh258

35. DiGiacomo M, Lewis J, Nolan MT, Phillips J, Davidson PM (2013) Health transitions in recently widowed older women: a mixed methods study. BMC Health Serv Res 13:143. https://doi.org/10. 1186/1472-6963-13-143

36. Rosman L, Dunsiger S, Salmoirago-Blotcher E (2017) Cumulative impact of stressful life events on the development of Takotsubo cardiomyopathy. Ann Behav Med 51(6):925-930. https://doi.org/ 10.1007/s12160-017-9908-y

37. Tivesten A, Vandenput L, Carlzon D, Nilsson M, Karlsson MK, Ljunggren Ö, Barrett-Connor E, Mellström D, Ohlsson C (2014) Dehydroepiandrosterone and its sulfate predict the 5-year risk of coronary heart disease events in elderly men. J Am Coll Cardiol 64(17):1801-1810. https://doi.org/10.1016/j.jacc.2014.05.076

38. Badcock JC, Dehon H, Laroi F (2017) Hallucinations in healthy older adults: an overview of the literature and perspectives for future research. Front Psychol 8:1134. https://doi.org/10.3389/fpsyg. 2017.01134

39. Monk TH, Germain A, Reynolds CF (2008) Sleep Disturbance in Bereavement. Psychiatr Ann 38(10):671-675

40. Cauley JA, Hovey KM, Stone KL, Andrews CA, Barbour KE, Hale L, Jackson RD, Johnson KC, LeBlanc E, Li W, Zaslavsky O, OchsBalcom H, Wactawski-Wende J, Crandall CJ (2019) Characteristics of self-reported sleep and the risk of falls and fractures: the Women's Health Initiative (WHI). J Bone Miner Res 34(3):464 474. https://doi.org/10.1002/jbmr.3619

41. Zisook S, Shuchter SR, Sledge PA, Paulus M et al (1994) The spectrum of depressive phenomena after spousal bereavement. J Clin Psychiatry 55(Suppl):29-36

42. Valdimarsdottir U, Helgason AR, Furst CJ, Adolfsson J et al (2003) Long-term effects of widowhood after terminal cancer: a Swedish nationwide follow-up. Scand J Public Health 31(1):31-36

43. Marcum ZA, Perera S, Thorpe JM, Switzer GE, Castle NG, Strotmeyer ES, Simonsick EM, Ayonayon HN, Phillips CL, Rubin S, Zucker-Levin AR, Bauer DC, Shorr RI, Kang Y, Gray SL, Hanlon JT, Health ABC Study (2016) Antidepressant use and recurrent falls in community-dwelling older adults: findings from the health ABC study. Ann Pharmacother 50(7):525-533. https:// doi.org/10.1177/1060028016644466

44. Pochard F, Azoulay E, Chevret S, Lemaire F, Hubert P, Canoui P, Grassin M, Zittoun R, le Gall JR, Dhainaut JF, Schlemmer B, French FAMIREA Group (2001) Symptoms of anxiety and depression in family members of intensive care unit patients: ethical hypothesis regarding decision-making capacity. Crit Care Med 29(10):1893-1897

45. Haines KJ, Denehy L, Skinner EH, Warrillow S, Berney S (2015) Psychosocial outcomes in informal caregivers of the critically ill: a systematic review. Crit Care Med 43(5):1112-1120. https://doi.org/ 10.1097/CCM.0000000000000865

46. Turner M, King C, Milligan C, Thomas C, Brearley SG, Seamark D, Wang X, Blake S, Payne S (2016) Caring for a dying spouse at the end of life: 'it's one of the things you volunteer for when you get married': a qualitative study of the oldest carers' experiences. Age Ageing 45(3):421-426. https://doi.org/10.1093/ageing/afw047

Publisher's note Springer Nature remains neutral with regard to jurisdictional claims in published maps and institutional affiliations. 